\title{
Binder Behavior on Chromite-Carbon Composite Pellets
}

\author{
Adolfo Pillihuaman Zambrano ${ }^{a}$, Cyro Takano $^{b}{ }^{*}$, Marcelo Breda Mourao $^{b}$, Solon Yasuhiko Tagusagawa ${ }^{b}$ \\ ${ }^{a}$ Section of Mining Engineering, Pontifical Catholic University of Peru, Av. Universitaria 1801, San \\ Miguel, Lima 32, Peru \\ ${ }^{b}$ Department of Metallurgical and Materials Engineering, University of Sao Paulo, Av. Prof. Mello \\ Moraes, 2463, São Paulo, SP, Brazil
}

Received: March 31, 2016; Revised: August 05, 2016; Accepted: September 04, 2016

\begin{abstract}
The influence of binders on the mechanical properties of chromite, self-reducing pellets, after subjecting to high temperatures, is analyzed in this paper. Bentonite, sodium silicate, and a combination of bentonite with carboxymethyl cellulose (CMC) were tested with different contents. All of the raw materials were characterized by chemical analysis and particle size distribution. The materials were pelletized (P1 to P7). All of the bounded green and dried pellets (P2 to P7) achieved the desired mechanical strengths, and none presented decrepitation. The best performance was obtained by the pellet P7 (4\% sodium silicate as binder), with the green strength of $34 \mathrm{~N} /$ pellet, the dried strength of $50 \mathrm{~N} /$ pellet, and the strength was higher than $110 \mathrm{~N} /$ pellet after heat treatment at critical temperatures between 1173 and $1373 \mathrm{~K}$. The unitary reduction reaction fraction was achieved after 10 minutes, at $1773 \mathrm{~K}$.
\end{abstract}

Keywords: Ferrochromium, Self-reduction, Self-reducing pellets, Chromite

\section{Introduction}

According to Mantovani ${ }^{1}$, Marcheze ${ }^{2}$ and Zambrano ${ }^{3-6}$, the production of high-carbon ferrochrome using carbon composite pellets by the self-reduction process at the laboratory level is a process that presents technological advantages. Some features are the usage of fine chromite ore and reducing agents and high efficiency and high productivity resulting from a high reaction rate, reaching almost unit reduction reaction fraction in 5-10 minutes at $1773 \mathrm{~K}$. In the conventional process, the $\mathrm{Cr}$ yield recovery is approximately $85 \%$ compared with $95 \%$ recovery by the self-reducing process.

Self-reducing processes, in general, need to satisfy two important characteristics ${ }^{3-6}$. Energy should be supplied to the agglomerate for a highly endothermic reduction reaction, and, more importantly, the cold-bonded agglomerate should have enough strength without degradation throughout the entire process.

The self-reducing chromite pellets using Portland cement as a binder require more than $10 \%$ Portland cement to achieve cold strength for handling and loading into electrical furnaces. The hydration reaction of cement confers good cold strength at temperatures up to approximately 973 $\mathrm{K}$, when the dehydration starts. For higher temperatures, mainly above $1173 \mathrm{~K}$, the degradation is higher due to more intense dehydration coupled with reduction reactions. This phenomenon is critical for iron ore pellets because the strength decreases in the temperature range of 973-1223 K. For the carbothermic reduction of chromite, the reduction starts at

\footnotetext{
* e-mail: cytakano@usp.br
}

temperatures higher than $1473 \mathrm{~K}$, which is an advantage because the process avoids additional degradation, and at this temperature, the strength is enhanced by the sintering process.

The objective of this work is to evaluate the behavior of different binders to agglomerate carbon composite chromite ore, with emphasis on the temperature range of 1173-1573 K.

The alternative binders tested were bentonite, with or without the addition of CMC (Carboxymethylcellulose), and sodium silicate.

Bentonite is the most commonly used binder for the traditional pelletizing process of iron ore. The unique structure of bentonite allows more than 10-fold water absorption, forming a colloid with dispersed submicron-platelets (viscous slurry phase), and improving ballability. With $0.7 \%$ content in iron ore, the green (wet) strength reaches approximately $10 \mathrm{~N} /$ pellet. After drying, these platelets stick to the surface of ore particles, acting as a bridge, and the strength increases to 22-25 N/pellet ${ }^{7}$. Of the many types of bentonite, sodium bentonite is the most effective. Sodium bentonite presents higher water absorption and consequently higher dispersion of platelets than calcium bentonite ${ }^{8}$. The sodium content also forms an indigenous slag phase during induration (liquid phase sintering) such that at $773 \mathrm{~K}$, the strength reaches 100 $\mathrm{N} /$ pellet, and at $973 \mathrm{~K}$, the strength reaches $400 \mathrm{~N} /$ pellet $^{9}$.

Sodium silicate is an inorganic polymer that can form chains and cross-linked structures that act as binders and is commonly represented by the main components $\mathrm{Na}_{2} \mathrm{O}$ and $\mathrm{SiO}_{2}$. The properties depend on the ratio between the main components. Sodium silicate is known as "alkaline" when the weight ratio of $\mathrm{SiO}_{2}: \mathrm{Na}_{2} \mathrm{O}$ is smaller than 3.22. The binding 
mechanism is due to precipitation of silica gel, sodium silicate and silicic acid. Curing by heating or by $\mathrm{CO}_{2}$ fluxing results in a polysilic acid polymer, which acts as a binder. Sodium silicate is commonly used as binder for foundry sands ${ }^{10}$.

Carboxymethylcellulose is an organic polymer derived from high solubility cellulose in water and is frequently used as a stabilizer and binder. It presents high efficiency as binder for conferring strength, mainly as wet stage of agglomerates and satisfy important requisites for binders ${ }^{11}$ : i) hydrophilic functional groups to promote binder dispersion into moisture and to enforce concentrate wettability; ii) polar functional groups to promote binder adhesion to ore particles; and iii) mechanically strong and thermally stable. CMC with higher molecular weight presents higher viscosity conferring higher wet drop strength but do not alter the wet and dry compression strength ${ }^{12}$.

\subsection{Desired strengths of pellets with an average $12 \mathrm{~mm}$ diameter}

The accepted desired strengths for green and dried pellets to avoid excessive degradation during processing, which increases recycling volume, are:

Wet pellets: $10 \mathrm{~N} /$ pellet $^{13}$ and

Dried pellets: $20-25 \mathrm{~N} /$ pellet $^{13}$.

During the reduction process at temperatures above $773 \mathrm{~K}$ : i) for conventional indurated pellets, the accepted value is $1500 \mathrm{~N} /$ pellet for use in large blast furnaces ${ }^{11}$; and ii) for composite pellets, the value is still an open question because it depends on the reactor that is used, according to the high temperature strength behavior of cold-bonded pellets. The ideal behavior for composite pellets should be self-induration during heating and reduction.

\section{Raw Materials and Methods}

The raw materials used were Brazilian chromite ore (Jacurici mine), petroleum coke, ferrosilicon fines, bentonite, CMC (powder) and sodium silicate as binders (liquid). Tables 1, 2, 3 and 4 show the chemical compositions, microanalysis of phases, particle size analysis of the materials and pellet compositions, respectively.

Table 2 presents the microanalysis results determined by EDS of the phases shown in Figure 1. The Chromite phase ( $\mathrm{XO} . \mathrm{Y}_{2} \mathrm{O}_{3}$ ) is homogeneous, containing mainly $\mathrm{X}=$ divalent cations of $\mathrm{Fe}$ and $\mathrm{Mg}$, and $\mathrm{Y}=$ trivalent cations of $\mathrm{Cr}, \mathrm{Al}$ and $\mathrm{Fe}^{14}$, but the gangue contains phases of magnesium silicate (gangue 1) and aluminum silicate (gangue 2).

First, all the solid raw materials were dried and mixed in a turbula mixer (67rpm, during 2400s) for each composition. Liquid sodium silicate was added to the previous mixture and, then proceeded with further mixing. The moisture was controlled to $10 \%$. The pellets were made manually and the diameter was controlled to $15 \mathrm{~mm}$ by using a round perforated steel sheet. Crushing strength was determined for wet, after aging (at normal atmosphere and room temperature), drying and after submitted to heat treatment. The pellets, which presented good performance of strength at high temperature, were elected to proceed with reduction test, at $1773 \mathrm{~K}$. The procedures of these tests are given ahead.

Conventional mechanical EMIC (INSTRON) press of 30 ton capacity press, with acquisition data system, with load cell for 10 and $500 \mathrm{kgf}$ were used for measuring the crushing (compression) strength.

To evaluate the performance of a binding agent in selfreducing pellets, the procedure for iron ore pellets was adopted.

\subsection{Compression Strength of wet Self-reducing Pellets}

These tests were performed immediately after pelletizing. The procedure was as follows: 15 pellets were chosen randomly. Each was submitted to the compression test. The average of the values was taken as the result of the test.

\subsection{Compression Strength of Dry Pellets}

Drying process: $393 \mathrm{~K}$ for 3 hours. The procedure: 15 pellets were chosen randomly. After cooling in air, one-byone, the pellets were submitted to the compression test. The average of the values was the result of the test.

\subsection{Mechanical Behavior Experiments at High Temperatures}

The chromite self-reducing pellets previously dried at $393 \mathrm{~K}$ for 3 hours were submitted to thermal cycles (1173, $1273,1373,1473$ and $1573 \mathrm{~K})$. A tube vertical furnace (Lindberg Blue), with SiC resistance, with flow of pure argon, was heated previously to the given temperatures and then the dried pellets in an alumina crucible, at room temperature, were directly submitted at test temperature and kept them for 30 minutes. After that, the samples were cooled in argon atmosphere.

The crushing strength procedure: 15 pellets were taken randomly, and one-by-one, the pellets were subjected to compression tests. The average of these values was the result of the test.

\subsection{Decrepitation Experiments}

The pellets were submitted to decrepitation experiments with following procedure: 32 pellets were dried at $413 \mathrm{~K}$ for 4 hours and were then submitted to thermal shock, keeping 5 minutes at $1273 \mathrm{~K}$, with the same furnace and same procedures described at 2.3.

Calculation of decrepitation index: $\mathrm{DI}=$ (number of decrepitated pellets x 100)/32 
Table 1: Chemical composition of the materials (wt $\%$ )

\begin{tabular}{|c|c|c|c|c|c|}
\hline Components & Chromite ore & Petroleum Coke & $\mathrm{Fe}-\mathrm{Si}$ & Sodium Silicate & Bentonite \\
\hline $\mathrm{Cr}_{2} \mathrm{O}_{3}$ & 41.2 & & & & \\
\hline $\mathrm{FeO}$ & 16.9 & & & & 7.3 \\
\hline $\mathrm{SiO}_{2}$ & 5.7 & & & 27.6 & 55.7 \\
\hline $\mathrm{Al}_{2} \mathrm{O}_{3}$ & 17.3 & & & & 28.4 \\
\hline $\mathrm{MgO}$ & 15.6 & & & & 2.8 \\
\hline $\mathrm{CaO}$ & 0.4 & & & & 1.0 \\
\hline Volatile material & & 10.8 & & & \\
\hline Fe total & 13.1 & & 25.0 & & \\
\hline $\mathrm{P}$ & 0.007 & & & & \\
\hline C fix & & 88.8 & & & \\
\hline Ash & & 0.4 & & & \\
\hline S & & 0.8 & & & \\
\hline $\mathrm{Si}$ & & & 4.16 & & \\
\hline $\mathrm{Ca}$ & & & 0.14 & & \\
\hline $\mathrm{ZnO}$ & & & & & 2.8 \\
\hline $\mathrm{Na}_{2} \mathrm{O}$ & & & & 8.6 & \\
\hline $\mathrm{H}_{2} \mathrm{O}$ & & & & 63.5 & \\
\hline Others & & & & & \\
\hline
\end{tabular}

Table 2: Microanalysis (wt $\%$ ) by EDS of the phases shown in figure 1

\begin{tabular}{lllllllll}
\hline area & $\mathrm{O}$ & $\mathrm{Mg}$ & $\mathrm{Al}$ & $\mathrm{Si}$ & $\mathrm{Ca}$ & $\mathrm{Cr}$ & $\mathrm{Fe}$ & identification \\
\hline 1 & 12 & 12 & 15 & 0.7 & 0.3 & 42 & 18 & chromite \\
2 & 27 & 23 & 1.5 & 42 & 0.4 & 1.2 & 4.3 & gangue 1 \\
3 & 14 & 11 & 14 & 0.5 & 0.3 & 41 & 20 & chromite \\
4 & 20 & 0.5 & 16 & 61 & 1.4 & 0.8 & 0.5 & gangue 2 \\
5 & & & & & & & & \\
\hline
\end{tabular}

Table 3: Particle size of the materials (wt $\%$ )

\begin{tabular}{lcccccc}
\hline Mesh & Opening $(\mu \mathrm{m})$ & Chromite & Petroleum coke & Bentonite & Fe-Si & CMC \\
\hline 100 & 147 & 100 & $<100$ & $<100$ & 100 & 80.8 \\
150 & 104 & 99.3 & & & 26.0 & $<100$ \\
200 & 74 & 79.0 & & & 4.0 & 1.4 \\
270 & 53 & 26.6 & & & 0.00 \\
400 & 38 & 2.8 & & & \\
-400 & & 0.00 & & & & \\
\hline
\end{tabular}

Table 4: Composition of the pellets (wt $\%$ )

\begin{tabular}{lcccccc}
\hline Components & Chromite & $\begin{array}{c}\text { Petroleum Coke } \\
(20 \% \text { excess })\end{array}$ & Fe-75\%Si & $\begin{array}{c}\text { Sodium Silicate } \\
\text { (hydrated) }\end{array}$ & Bentonite & CMC \\
\hline P1 & 80.1 & 17.9 & 2 & - & 0.0 & 0.0 \\
P2 & 79.5 & 17.8 & 2 & - & 0.75 & 0.0 \\
P3 & 79.3 & 17.7 & 2 & - & 1.0 & 0.0 \\
P4 & 79.1 & 17.7 & 2 & - & 1.0 & 0.2 \\
P5 & 79.3 & 17.7 & 2 & $1(2.7)$ & - & - \\
P6 & 78.4 & 17.6 & 2 & $2(5.5)$ & - & - \\
P7 & 76.8 & 17.2 & 2 & $4(11.0)$ & - & - \\
\hline
\end{tabular}




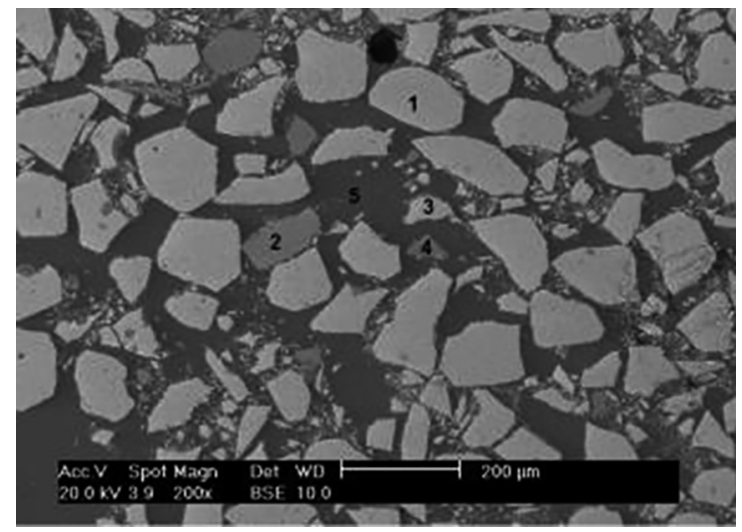

Figure 1: SEM of the chromite ore. Chromite particles (lighter) and gangue (darker).

\subsection{Reduction Tests}

An induction furnace with $30 \mathrm{~kW}$ and $3 \mathrm{kHz}$ in combination with graphite suceptor was used, which is describe elsewhere ${ }^{5}$.

The experimental procedure was as follow:

- The green pellet was completely dried (393K, 3 hours).

- The graphite crucible coated with alumina was positioned inside the suceptor.

- The induction furnace was turned on, and the temperature was monitored to keep it at the settled temperature of the experiment of $1773 \mathrm{~K}$.

- When the experimental temperature was achieved, the dried pellet was carefully dropped inside the graphite crucible, coated with alumina.

- The pellet was kept for 1, 2, 5 and 10 minutes at the temperature.

- Once completed the reaction time at the temperature, the graphite crucible was taken out and quickly cooled down to room temperature with argon flow (4L/min), stopping the reduction reaction and protecting the reduced products.

- The weight loss of the pellet was registered.

The end of the reaction was considered when maximum fraction weight loss of the pellet was achieved, that is, keeping it during enough time to ensure constant weight.

The reaction fraction was defined according to equation (1)

$$
F r=\frac{W_{i}-W_{t}}{k_{W} \cdot W_{t}}
$$

Where:

Fr: Reaction fraction;

$\mathrm{W}_{\mathrm{i}}$ : Initial weight of dried pellet (in $\mathrm{g}$ );

$\mathrm{W}_{\mathrm{t}}$ : Pellet weight after time $\mathrm{t}$ at given temperature (in g); $\mathrm{k}_{\mathrm{w}}$ : Maximum fraction weight loss of the considered pellet; $\mathrm{t}$ : Predetermined time of experiment.
Each pre-reduced pellet was carefully cut and the cross section was examined by scanning electron microscope.

\section{Results and Discussion}

\subsection{Compression Strength of Self-reducing Pellets}

Figure 2 shows the strength of the pellets under wet and dried conditions. Pellets with no binder (P1) did not reach the desired strength under wet and dried conditions. Pellets with bentonite (P3), bentonite plus CMC (P4) and with sodium silicate presented good performance. The best results were obtained with $4 \%$ sodium silicate (P7). Even with $18 \%$ petroleum coke in the pellet, the results with the addition of $0.75 \%$ bentonite (P2) were satisfactory.

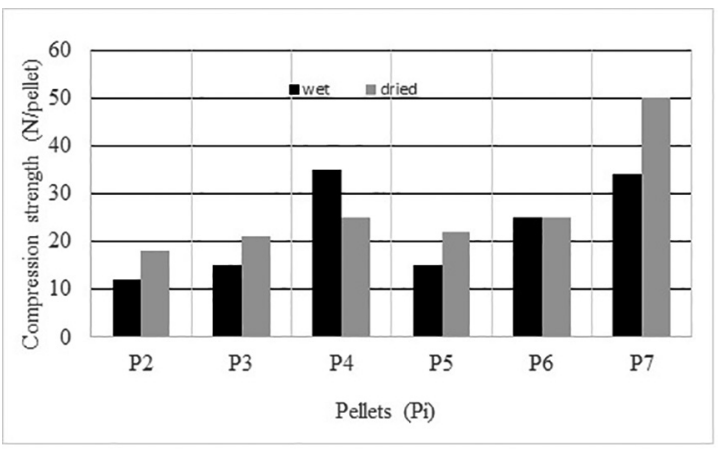

Figure 2: Compression strength of pellets under wet and dried conditions.

In Figure 2, the P4 ( $1 \%$ bentonite $+0.2 \%$ CMC) shows that the wet strength more than doubled compared with P3 (1\% bentonite), but the dried strength of the pellet P4 presented only a small improvement. Observe that only the pellet $\mathrm{P} 4$ presented a decrease in strength after drying, showing that CMC loses efficiency at dried condition but it improved 20\% with relation to pellet P3 (without CMC).

The results of the compression strength of pellets with different binders, after heat treatment during 30 minutes, at varying temperatures before reduction.are shown in Figure 3 , before chromium reduction. The views of the behaviors at different times were similar and they are not shown here.

In the range of critical temperatures for cementitious-binded, self-reducing pellets between $1173 \mathrm{~K}$ and $1373 \mathrm{~K}$, none of pellets had enough strength to support the traditional reduction process.

Dried pellets with bentonite (P2, P3 and P4) started increasing in strength only at $1473 \mathrm{~K}$ and increased sharply at $1573 \mathrm{~K}$, reaching approximately $80 \mathrm{~N} /$ pellet. This strength or higher was obtained by P5 at $1473 \mathrm{~K}$, by P6 at 1373 $\mathrm{K}$, and by $\mathrm{P} 7$ at $1173 \mathrm{~K}$ (4\% sodium silicate). The better performance of sodium silicate was credited to the formation of an indigenous liquid phase, which helps the sintering. The 


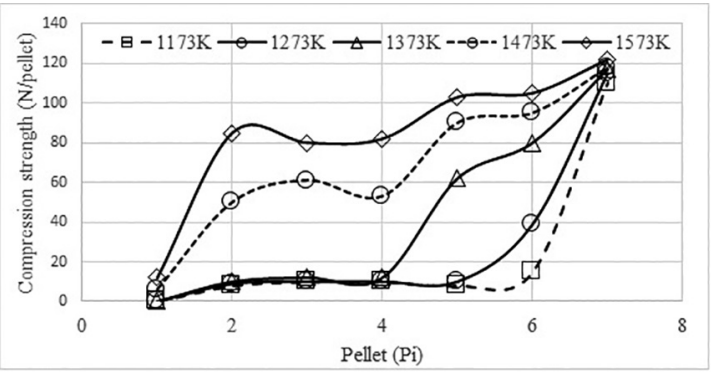

Figure 3: Effect of temperature on the compression strength of pellets with different binders after heat treatment during 30 minutes at varying temperatures before reduction.

sodium silicate used was at the eutectic composition $(75 \%$ mole of $\mathrm{SiO}_{2}$ ), indicating eutectic temperature around $965 \mathrm{~K}$.

The best result was obtained with the $4 \%$ addition of sodium silicate (P7). Figure 4 shows that the strength increased sharply up to 60 minutes at all tested temperatures. After this time, the effect was small.

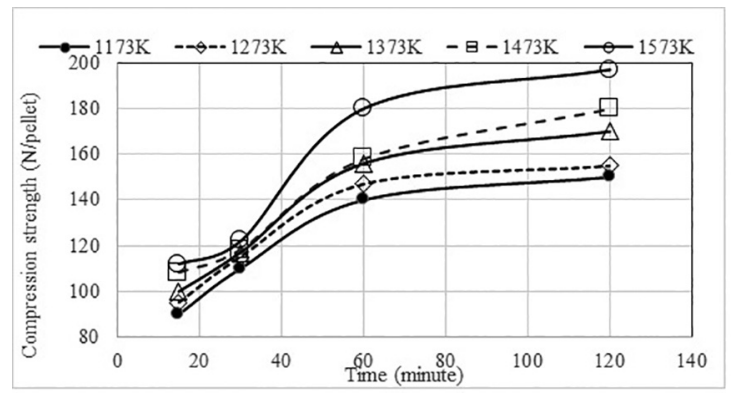

Figure 4: Influence of time and temperature on the strength of pellet P7 (4\% sodium silicate).

The liquid phase sintering increases the strength with increasing temperature and increasing time of exposure. Figure 4 shows that, at the temperature of $1573 \mathrm{~K}$, the chromite particles were linked with a previous liquid phase, which incorporated the gangue phase of the chromite ore (area 4 of Figure $5 \mathrm{~b}$ and Table 5).The results of the microanalysis in Table 5 are consistent with the phases contained in chromite ore (Table 2, Figure 1). The composition of area 4 in Table 5 shows that more gangue 2 is participating to form the liquid phase in that area.

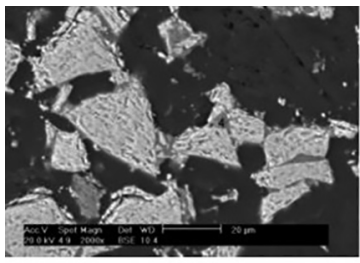

(a)

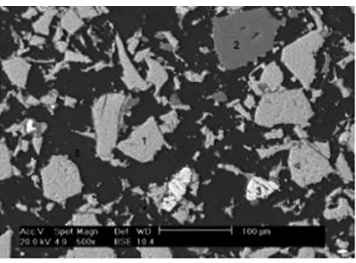

(b)
Figure 5: Backscattered electrons of the P7 pellet ( $4 \%$ sodium silicate) after $1573 \mathrm{~K}$ for 120 minutes (a) 500x, (b) 2000x.

\subsection{Effect of the aging of wet pellets with sodium silicate}

Figure 6 shows that the green pellets with sodium silicate lost their strength with aging and that the loss was more intense with higher sodium silicate content. This behavior is credited to the hygroscopic behavior of sodium silicate. This behavior was not observed for pellets bonded with bentonite.

\subsection{Decrepitation}

Pellets P1 to P7 were tested at temperatures of 1173, $1273,1373,1473$ and $1573 \mathrm{~K}$ for 5 minutes to evaluate the decrepitation index (DI), and all of the results were zero, showing that the chromite self-reducing pellets tested were not susceptible to decrepitation.

\subsection{Reduction experiment}

The P7 pellet, which presented the best results for compression strength, was used to analyze the reduction behavior.

Figure 7 shows the reduction evolution of the $\mathrm{P} 7$ pellet with $4 \%$ sodium silicate at $1773 \mathrm{~K}$, which reached the unitary reduction fraction after 10 minutes.

After the reduction experiments, $\mathrm{P} 7$ pellets, tested at $1773 \mathrm{~K}$, were examined metallographically in a scanning electronic microscope to observe the reduction evolution, as shown in Figures 8.

The reduction evolution of self-reducing chromite pellets is shown in Figures 7 and 8. Small particles of chromite were quickly reduced completely, carburized and coalesced with the help of the slag (Figure 8c). The slag (initial, intermediary and final) compositions in Table 6 present liquid temperatures lower than $1773 \mathrm{~K}$. Larger

Table 5: Chemical composition in the core of the P7 pellet analyzed by backscattered electrons by scanning electron microscopy after $1573 \mathrm{~K}$ (120 minutes) (wt\%)

\begin{tabular}{lcccccccc}
\hline area & $\mathrm{O}$ & $\mathrm{Mg}$ & $\mathrm{Al}$ & $\mathrm{Si}$ & $\mathrm{Ca}$ & $\mathrm{Cr}$ & $\mathrm{Fe}$ & Phase \\
\hline 1 & 14.6 & 16.7 & 15.6 & 0.3 & 0.3 & 41 & 11 & chromite \\
2 & 26.4 & 27 & 1.2 & 40 & 0.2 & 1.5 & 6 & gangue 1 \\
3 & 14.4 & 14 & 14.2 & 0.1 & 0.2 & 41 & 16 & Chromite partially reduced \\
$4(*)$ & 20.3 & 23.1 & 3.3 & 43 & 0.9 & 2 & 5.6 & Binder plus gangue \\
5 & & void & & & & & & \\
\hline
\end{tabular}

(*) sodium not determined. 


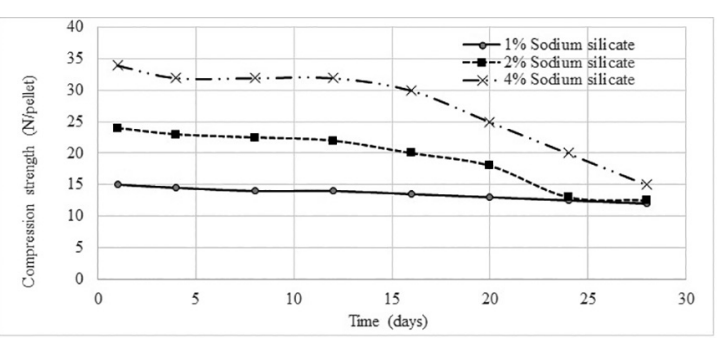

Figure 6: Compression strength of chromite self-reducing pellets (P5, P6 and P7) bound with 1, 2 and 4\% sodium silicate.

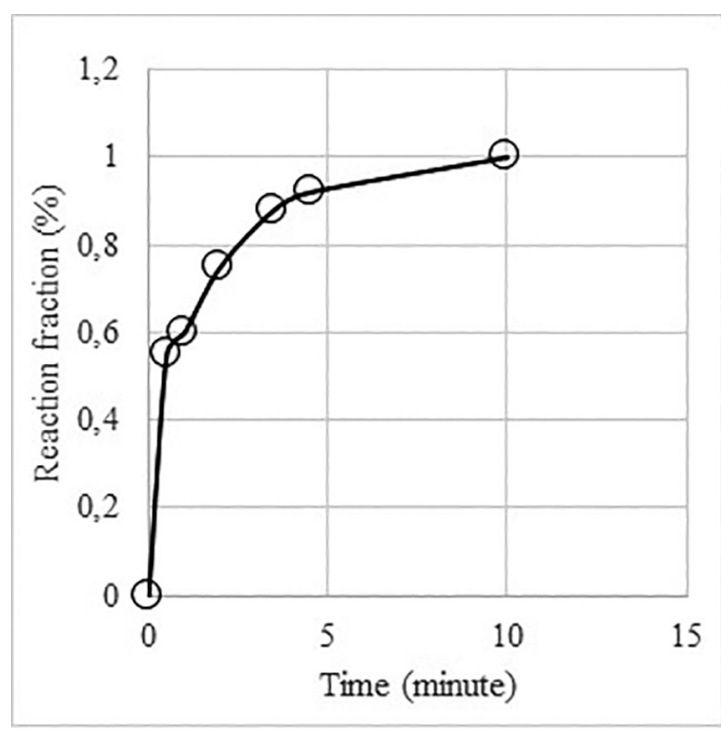

Figure 7: Reduction evolution at $1773 \mathrm{~K}$ of the pellet P7.

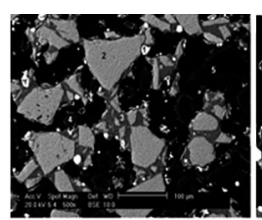

(a)

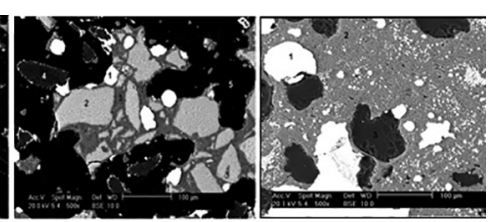

(b)

(c)
Figure 8: Self-reducing chromite pellet bound with $4 \%$ sodium silicate partially reduced at $1773 \mathrm{~K}$ for: a) 1 ; b) 2 and c) $10 \mathrm{~min}$. Reaction fraction of $0.6 ; 0.75$ and 1 , respectively. SEM backscattered. particles of chromite were partially reduce ${ }^{15}$ because the chromium content increased from $28 \%$ in the original chromite particle to $41 \%$ after 1 minute at $1773 \mathrm{~K}$. This pre-reduction level remained after 2 minutes, which indicates that the next reduction stage was reached with more stable oxides (sub-oxides in chromite).

Figure 8 b,c show that partially reduced chromite particles were covered by slag more intensively after 2 minutes. Compared with the results of the previous work ${ }^{3}$, there is an indication that slag formation, enhanced by sodium silicate, harmed the gas/solid reaction, resulting in a longer time to reach complete reduction. The reduction reaction was very fast if enough energy was supplied for a strong endothermic reaction. The chromium content in the slag decreased from $5.3 \%$ to $0.7 \%$ in the final slag.

\section{Conclusions}

The conclusions of the chromite ore-coke composite pellets bound with bentonite and sodium silicate are:

- All of the tested dosages of binders presented green pellets with compression strengths within the desired value (higher than $10 \mathrm{~N} /$ pellet). The addition of $0.2 \% \mathrm{CMC}$ to pellets with $1 \%$ bentonite doubled the green strength, reaching $35 \mathrm{~N} /$ pellet;

- Dried pellets presented compression strengths higher than 20-22 N/pellet, except the pellet with $0.75 \%$ bentonite. As expected, the addition of $0.2 \%$ $\mathrm{CMC}$ to the pellet with $1 \%$ bentonite only slightly improved the strength of the dried pellet;

- The best results for the mechanical properties under the wet and dried conditions were obtained with $4 \%$ sodium silicate;

- In the temperature range of $1173-1573 \mathrm{~K}$, none of the binders and dosages reached the desired strength of the fired iron pellets used in conventional reduction processes, such as blast furnaces. A compression strength of 110-122 N/pellet was reached with $4 \%$ sodium silicate after heating for 30 minutes in the range of $1173 \mathrm{~K}-1573 \mathrm{~K}$;

Table 6: Chemical composition (wt $\%$ ) of the core of the P7 pellet analyzed by EDS in SEM after reduction for 1, 2 and 10 minutes at $1773 \mathrm{~K}$

\begin{tabular}{|c|c|c|c|c|c|c|c|c|c|c|c|c|}
\hline Area-Figure & Phase/identification & $\mathrm{O}$ & $\mathrm{C}$ & $\mathrm{Na}$ & $\mathrm{Mg}$ & $\mathrm{Al}$ & $\mathrm{Si}$ & $\mathrm{Ca}$ & $\mathrm{P}$ & $\mathrm{S}$ & $\mathrm{Cr}$ & $\mathrm{Fe}$ \\
\hline 1-Fig 8a & & & 7.6 & & & & 0.4 & & 0.2 & 0.14 & 68 & 24 \\
\hline 1-Fig $8 b$ & $\mathrm{Fe}-\mathrm{Cr}$ & - & 8.1 & - & - & - & 0.6 & - & 0.2 & 0.18 & 64 & 27 \\
\hline 1-Fig 8c & & - & 8.4 & - & - & - & 0.5 & - & 0.3 & 0.19 & 62 & 29 \\
\hline 2-Fig $8 \mathrm{a}, 8 \mathrm{~b}$ & Chromite grain, partially reduced & 15 & & & 15 & 14 & 0.2 & 0.2 & & & 41 & 14 \\
\hline 3-Fig 8a & Initial slag & 27 & - & n.d. & 11 & 18 & 38 & 0.16 & - & & 5.3 & 0.7 \\
\hline 3-Fig 8b & Intermediary slag & 25 & - & 3.1 & 25 & 9 & 34 & 0.15 & - & - & 3.6 & 0.6 \\
\hline 2-Fig 8c & Final slag & 26 & - & 1.1 & 25 & 9 & 38 & 0.20 & - & - & 0.7 & 0.2 \\
\hline 4-Fig $8 b$ & Petroleum coke & & & & & & & & & & & \\
\hline 5 & void & & & & & & & & & & & \\
\hline
\end{tabular}


- No decrepitation was observed in the pellets with binders; and.

- $\quad$ The $4 \%$ of sodium silicate lowered the reduction rate by enhancing the slag formation. The reaction fraction reached 0.91 and 1 at $1773 \mathrm{~K}$ after 5 and 10 minutes, respectively.

\section{Acknowledgements}

FAPESP (Research Foundation of the State of Sao Paulo), CNPq (National Council for Scientific and Technological Development) and Pontificia Universidad Catolica del Peru.

\section{References}

1. Mantovani MC. Comportamento a frio e a quente de pelotas auto-redutoras de resíduo de aciaria elétrica. [Dissertation]. São Paulo: Polytechnic School of University of São Paulo; 1998.

2. Marcheze ES. Resistência mecânica a frio e crepitação em pelotas auto-redutoras. [Dissertation]. São Paulo: Polytechnic School of the University of São Paulo; 1994.

3. Takano C, Zambrano AP, Nogueira AEA, Mourao MB, Iguchi Y. Chromites Reduction Reaction Mechanisms in CarbonChromites Composite Agglomerates at 1773 K. ISIJ International. 2007;47(11):1585-1589.

4. Zambrano AP, Takano C, Mourao MB, Tagusagawa ST. High Carbon Ferro-Chromium by Self-Reducing Process. Journal of Iron and Steel Research International. 2009;16:1342-1346.

5. Zambrano AP, Takano C, Nogueira AEA, Mourao MB, Tagusagawa ST, Iguchi Y. High Carbon Ferro-chromium by Self-Reducing Process: Effects of Fe-Si and fluxing agent additions. ISIJ International. 2011;51(8):1296-1300.
6. Zambrano AP, Takano C, Nogueira AEA, Mourao MB, Tagusagawa ST. The reduction of self-reducing chromite pellets at $1773 \mathrm{~K}$ intrapellet gradients. International Journal of Research and Reviews in Applied Sciences. 2012;13(1):330-339.

7. Srivastava U, Kawatra SK, Eisele TC. Study of organic and inorganic binders on strength of iron oxide pellets. Metallurgical and Materials Transaction B. 2013;44(4):1000-1009.

8. Clem AG, Doehler RW. Industrial applications of bentonite. Clays Clay Miner. 1961;10:272-283.

9. Sunde M. Organic binder as substitute for bentonite in ilmenite pelletization. [PhD Thesis]. Trondheim: NTNU - Norwegian University of Science and Technology. Dept. of Materials Science and Engineering; 2012.

10. Eisele TC, Kawatra SK. A review of binders in iron ore pelletization. Mineral Processing and Extractive Metallurgy Review. 2003;24(1):1-90.

11. Qiu G, Jang T, Huang Z, Zhu D, Fan X. Characterization of preparing cold bonded pellets for direct reduction using an organic binder. ISIJ International. 2003;43(1):20-25.

12. Goettzman HE, Bleifuss RL, Engesser J. An investigation of carboxymethylcellulose binders for taconite pelletizing. In: SME Annual Meeting; 1998 Jan 25-28; Phoenix, AZ, USA. Prepint no. 88-11

13. Halt JA, Kawatra SK. Review of organic binders for iron ore concentrate agglomeration. Minerals \& Metallurgical Processing. 2014;31(2):73-94.

14. Rocha MG, Da Silva AS, Mourao MB, Kurauch MHN, Takano C. Fundamental aspects of sintering of chromites concentrates. Mineral Processing and Extractive Metallurgy. 2014;123(4):251-256.

15. Beneduce F, Takano C. Carbothermic Reduction of Brazilian Chromites Ores Fines: Kinetics Behavior. In: Third JapanBrazil Symposium on Dust Processing-Energy-Environment in Metallurgical Industries; 2001 Oct 25-26; São Paulo, University of São Paulo, São Paulo, SP, Brazil. p. 15-24. 